\title{
Infidelidad: pasar del abismo a la grieta luego del acompañamiento terapéutico*
}

Cómo citar este artículo:

Salazar, N., Muñoz, D. y Builes, M. V. (2021).

Infidelidad: pasar del abismo a la grieta

luego del acompañamiento terapéutico.

Revista Latinoamericana de Estudios de

Familia, 13(2), 59-77.

https://doi.org/10.17151/rlef.2021.13.2.4

\author{
Natalia Salazar-Franco ** \\ Diana Muñoz-Santrich*** \\ María Victoria Builes-Correa ${ }^{* * * *}$
}

Recibido: 23 de enero de 2021

Aprobado: 10 de mayo de 2021

\begin{abstract}
Resumen: Objetivo. Reconocer los significados y las vivencias de la infidelidad antes y después del proceso terapéutico. Metodología. Investigación cualitativa, fenomenológica hermenéutica.

Se realizaron dos entrevistas semiestructuradas a tres parejas y una participante; triangulación de la información a través de un grupo de discusión con terapeutas. Resultados. La terapia facilitó la transformación de los significados; en infieles al pasar de una "ética del infiel" en tanto minimiza la infidelidad, a una postura crítica de sus actos; en infidelizados, pasó de una postura del blindaje e idealización de la pareja a comprenderla desde la fragilidad humana; ambos logran responsabilizarse, lo que permitió el tránsito de la vivencia inicial enmarcada en dolor y sensación del final de la relación, a la recuperación personal y relacional. Conclusión.

La terapia es un escenario que facilita transformar el "abismo" de la infidelidad a una "grieta", para así construir un presente y futuro más estético para ambos.
\end{abstract}

Palabras clave: infidelidad, significados, vivencias, terapia de pareja.

\footnotetext{
* El presente artículo de investigación es el producto del trabajo de grado "Terapia en infidelidad: puente de tránsito de la devastación al florecimiento", para optar al título de Magíster en Terapia Familiar y de Pareja de la Facultad de Medicina de la Universidad de Antioquia (Colombia).

${ }^{* *}$ Médica, Especialista en Sexología Clínica. Universidad de Antioquia. Medellín, Colombia.

E-mail: natalia.salazarf1@udea.edu.co. iD orcid.org/oooo-0oo2-4856-5145. Google Scholar

*** Médica. Universidad de Antioquia. Medellín, Colombia. E-mail: dianam.munoz@udea.edu.co.

(iD orcid.org/0000-0002-7157-9086. Google Scholar

Médica, Especialista en Terapia Familiar. Docente titular, Universidad de Antioquia. Medellín, Colombia. E-mail: maria.builes@udea.edu.co. (DD orcid.org/oooo-0002-7802-8615. Google Scholar
} 


\title{
Infidelity: moving from the abyss to the rift after therapeutic support
}

\begin{abstract}
Objective. To recognize the meanings and experiences of infidelity before and after the therapeutic process. Methodology. Qualitative, hermeneutical phenomenological research. Two semistructured interviews were conducted with three couples and one participant. The triangulation of information was carried out through a discussion group with therapists. Results. The therapy facilitated the transformation of meanings: unfaithful participants moved from an "ethics of the unfaithful" to a critical position of their actions; the cheated participants went from a position of shielding and idealization of the couple to understanding them from human fragility. Both manage to take responsibility, which allowed the transition from the initial experience framed in pain and feeling of the end of the relationship, to personal and relational recovery. Conclusion. Therapy is a scenario that facilitates transforming the "abyss" of infidelity into a "rift", thus rebuilding a more aesthetic present and future for both.
\end{abstract}

Key words: infidelity, meanings, experiences, couple therapy.

\section{Introducción}

La infidelidad puede definirse como la ruptura de un contrato, acuerdo o pacto implícito o explícito, en el cual uno de los miembros de la pareja tiene algún tipo de relación con una tercera persona (Camacho, 2004; Morrissey et al., 2018). En la literatura se describen con frecuencia dos tipos: la infidelidad sexual, en la cual existe actividad sexual con otra persona que no es su compañero permanente, y la infidelidad emocional, cuando la persona ocupa su tiempo, esfuerzos, atención, romanticismo, en quien no es su pareja primaria (Urganci y Sakman, 2019). Se describe otro tipo, la infidelidad virtual, que es aquella relación sostenida a través de medios digitales (Posada y Noreña, 2015), también nombrada infidelidad cibernética o cibersexo (Scuka, 2015). Aunque existen distintas definiciones y tipos de infidelidades, estos pueden ser construidos desde una multiplicidad de significados que varían desde las culturas y las relaciones de pareja (Alfonso y Hernández, 2020). 
A nivel mundial, principalmente en estudios norteamericanos, la infidelidad tiene una prevalencia a lo largo de la vida, entre un $20 \%$ a $25 \%$ en parejas casadas (Fincham y May, 2016). En Colombia, la encuesta realizada por Datexco (2012) para el periódico El Tiempo en 13 ciudades del país, muestra que 6 de cada 10 parejas admiten haber sido infieles al menos una vez en sus vidas. Según el género, el $42 \%$ de las mujeres admitió haber sido infiel por lo menos alguna vez a su pareja, en comparación con los hombres en un 82\% (Datexco, 2012).

Otros aspectos que se han investigado ampliamente tienen relación con el impacto individual y de pareja que se genera posterior a un evento de infidelidad, como lo muestran los estudios realizados por Luyens y Vansteenwegen (2001), Charny y Parnass (2008), Giraldo y Garcés (2013), Roos et al. (2019) y Warach y Josephs (2019) que describen dicha experiencia como un estado de muerte, propia y de la pareja, un dolor intolerable, un trauma psicológico profundo, el cual ha sido asemejado con el estrés postraumático ya que suscita los mismos síntomas. Adicionalmente, al conocerse la infidelidad, los infieles pueden sentir negación y ambivalencia; la persona infidelizada puede experimentar choque, ira, odio, pérdida de la autoestima y la confianza sexual, entre otros. Dugal et al. (2018) informan que, según los terapeutas, uno de los problemas más prevalentes y difíciles de tratar en terapia de pareja es la infidelidad. A través del proceso terapéutico se logra disminuir la angustia y las parejas implementan nuevas herramientas que mejoran su relación (Ramos, 2013).

En Colombia, se hallaron cuatro estudios que tienen relación con el tema a investigar. El primero, de Jiménez (2016), describe que los consultantes llegaban con relatos negativos de sí y de la pareja, y posterior al proceso terapéutico se transformaron los significados, mejoraron su autoestima, la sexualidad y la comunicación. En el segundo, de Pérez et al. (2014), encontraron que la terapia tuvo un efecto en la disminución del problema, favoreciendo que cada miembro asumiera su rol en la situación sin importar si fue o no participante de la infidelidad. En el tercero, de Garciandía y Samper (2012), exponen cómo la terapia es un espacio para producir nuevos entendimientos que pueden ayudar a superar el evento. Por último, Giraldo y Garcés (2013) narran que las parejas construyen nuevas dinámicas relacionales asociadas al aprendizaje del episodio de infidelidad, siendo la terapia un escenario que permite significar la relación extramarital en la posibilidad de reconstrucción de la relación.

\section{Metodología}

La investigación se enmarca en el paradigma cualitativo, el cual busca la comprensión e interpretación desde las propias creencias, valores y reflexiones de sus actores. Apunta a profundizar los distintos fenómenos a partir de la perspectiva de 
los participantes y su singularidad, desde un ambiente natural y relacionado con el contexto (Hernández et al., 2010).

El método utilizado fue la fenomenología hermenéutica, la cual proporciona la comprensión de las experiencias favorecedoras del proceso terapéutico luego de la infidelidad, a través del lenguaje como herramienta que revela los significados construidos por las parejas (Hernández, et al., 2010; Creswell y Poth, 2016).

La población estuvo constituida por 3 parejas y una persona participante, seleccionadas por conveniencia y bola de nieve. Para la recolección de la información se utilizaron dos entrevistas semiestructuradas. En total se realizaron 8, durante agosto a diciembre de 2019, en la ciudad de Medellín, Antioquia. La duración promedio de cada entrevista fue de 90 minutos. Posteriormente, se realizó una tercera entrevista, modalidad virtual a la cuarta participante y un cuestionario vía correo electrónico a la pareja número tres entre los meses de julio y agosto de 2020, dado que por la contingencia asociada al Covid-19 no fue posible de manera presencial. Los participantes firmaron previamente el consentimiento informado, avalado por el Comité de Bioética de la Universidad de Antioquia.

Se realizó un grupo de discusión con cuatro terapeutas para la triangulación de la información, con la idea de analizar conceptos, emociones, experiencias y creencias acerca del acompañamiento terapéutico en infidelidad, lo que permitió generar significados grupalmente (Hernández et al., 2010). Tal evento se llevó a cabo en mayo de 2020 a través de una plataforma virtual, por la contingencia debida al Covid-19.

Para el grupo de discusión se contó con terapeutas con una experiencia mínima de cinco años en acompañamientos en infidelidad. Los criterios para participar consistían en personas mayores de edad, que consideraran el acompañamiento terapéutico como beneficioso en la continuidad de su relación y mantenimiento del vínculo erótico-afectivo (Tabla 1 ).

Tabla 1. Datos sociodemográficos participantes

\begin{tabular}{llcc}
\hline Participantes & Orientación sexual & Edad & Hijos(as) \\
\hline Girasol y Clavel & Pareja heterosexual & 39 años ambos & 1 \\
\hline Violeta y Tulipán & Pareja heterosexual & 35 y 37 años & 0 \\
\hline Lirio e Iris & Pareja heterosexual & 47 y 45 años & 1 \\
\hline Participante: Azalea & Pareja homosexual femenina & 32 años ambas & 0 \\
\hline
\end{tabular}

Fuente: elaboración propia. 
Se realizó un "análisis de contenido" inicialmente con la deconstrucción de los textos obtenidos de las entrevistas, que se codificaron a través del programa ATLAS. ti. A continuación, los códigos se agruparon en "categorías" a partir de las asociaciones que se encontraron entre ellos. En este artículo se presenta la categoría infidelidad, de la cual emergieron las subcategorías: significados (tránsito de la minimización y del blindaje al reconocimiento de la fragilidad humana) y vivencias (transitar del abismo a la grieta), las cuales se fueron nutriendo de las historias de los participantes. Se incorporó la reflexividad de las investigadoras para el informe final.

\section{Resultados y discusión}

Los resultados se muestran por grupos de infieles e infidelizados y se plasma la transformación de los significados y las vivencias asociados al acompañamiento terapéutico.

A través del relato, la palabra infiel corresponde a la persona que participa en la infidelidad, e infidelizada(o) es el otro miembro de la pareja.

\section{Primera subcategoría. Significados: tránsito de la minimización y del blindaje al reconocimiento de la fragilidad humana.}

Infieles. Antes del acompañamiento terapéutico.

A través de los relatos en tres personas infieles, previo a la terapia, se encuentra en común una perspectiva de minimizar la vivencia de la infidelidad, lo que posiblemente facilitó la autoaprobación de esta.

Para Clavel, la fidelidad era parte del contrato matrimonial, pero confinada al plano de lo emocional, consideraba la sexualidad como algo íntimo e individual. Se podía participar en una infidelidad siempre y cuando se aseguren unas prácticas para no hacer daño a su pareja.

La infidelidad para mí era... el plano sexual no entraba ahí, es algo tuyo. (Clavel, comunicación personal, 3 de diciembre de 2019) Incluso en las terapias, y ahí aprendí... es que cada quien se cree sus propias mentiras, hace una colección de momentos, los encaja de una manera, se vuelve su nuevo episodio ético. (Clavel, comunicación personal, 21 de agosto de 2019)

En el caso de Violeta, antes de asistir a terapia consideraba la infidelidad como algo injusto, sin embargo, refería una postura laxa frente a esta, que le permitía no profundizar en el significado y no considerar las consecuencias, lo importante era mantenerlo oculto, como una forma de protegerse a ella y a la pareja. 
Para mí antes era solo una palabra, como nunca había tenido ese dolor... tenía una visión más laxa, sabía que es algo que no es bueno y no es justo... antes sí lo tomaba como algo más tranquilo, porque nunca había sentido una consecuencia. (Violeta, comunicación personal, 4 de septiembre de 2019).

En Lirio, antes del proceso terapéutico y de saberse la infidelidad, su actuar estaba basado en dejarse llevar por las circunstancias sin dimensionar las consecuencias. Se percibía capaz de controlar la situación y disminuía el valor de lo que puede representar el descubrimiento de la infidelidad y la finalización de su relación. Narró: "antes, uno cree que no está haciendo algo malo... Vos crees que puedes controlar tus situaciones...Pero cuando ya estás en el punto, vos decís: ya la cosa es muy seria, realmente" (Lirio, comunicación personal, 20 de septiembre de 2019).

Azalea no presenta una perspectiva que minimiza la experiencia, para ella la infidelidad implica el involucramiento emocional. Antes del proceso terapéutico, nombra la metáfora "nublamiento", el cual describe como no poder ver con claridad y con mayor profundidad la situación. Esto lo relaciona con dos contextos: uno, el descubrimiento de la infidelidad y las reacciones emocionales del momento, y otro, a una especie de "disfraz", que permitía disminuir la visión crítica que se tenía de la relación, en la cual expresa no se sentía a gusto.

\begin{abstract}
[...] hay una noción de infidelidad... cuando metes tus sentimientos ahí... de alguna manera el corazón entro ahí. [...] nublamiento... no se veía realmente como toda la historia hacia atrás, que llevó a que esto pasara... una nube de cosas, que pongámoslo así la terapia ayuda a despejar del todo... incluso ir mucho más allá. (Azalea, comunicación personal, 3 de octubre de 2019)
\end{abstract}

Infieles. Después del acompañamiento terapéutico.

Posterior a la terapia, para los infieles, se transforma el significado y confluyen en una perspectiva crítica de la vivencia, donde se asume una responsabilización en el involucramiento con una tercera persona y también los actos para reparar.

Clavel entra a considerar que el evento trasciende de la esfera individual a lo privado de su relación, porque hay consecuencias en la vida de pareja, y también a lo público porque el episodio secreto llega al espacio terapéutico. Se transforma también en aceptar que la infidelidad incluye tanto el ámbito sexual como el emocional. Pronunció: "mi concepto finalmente de la fidelidad, es también de sentimientos, yo no le era fiel a los sentimientos. Y yo creo que ahí fue donde ya reaccioné y no tanto por sentirme culpable, sino porque miré las consecuencias" (Clavel, comunicación personal, 21 de agosto de 2019). 
A Violeta, al adquirir una apreciación crítica de la experiencia, le permite evaluar las consecuencias y reflexionar que no fue un evento insignificante, ni era posible asegurar no enfrentar consecuencias.

\begin{abstract}
No justifica ni el daño ni el dolor que se le hace ni a la persona ni a uno... uno siente que ha desgastado mucho tiempo y que finalmente no queda nada... tengo una visión de un antes y un después, creo que uno puede evitar los momentos. (Violeta, comunicación personal, 27 de noviembre de 2019).
\end{abstract}

Así mismo, Lirio, después de la terapia, resignifica a "esto fue un error", considera las consecuencias emocionales que permearon a su pareja, a él y a las familias. Además, algo que era considerado como banal, toma una forma de seriedad, gravedad y que no se puede controlar, por lo cual es un evento vital que quiebra una forma de pensamiento individual a una relacional o familiar que tiene en cuenta al otro. Expresó: "Ahora, vos sabes que sí hermano, cometiste un error, heriste muchas personas... Para mí es un error muy grave pues, porque recuperar la confianza es muy difícil" (Lirio, comunicación personal, 20 de septiembre de 2019).

Por último, Azalea, a través del diálogo con su pareja y la intermediación terapéutica, pasa a la claridad, las nubes fueron despejadas. Se asume una corresponsabilidad en la decisión de ambas, al abrir su relación como un juego, además, hay responsabilización de los actos propios. Por otro lado, no hay un cambio en el concepto mismo del evento; para ella, el involucramiento emocional es el que da cuenta de la infidelidad, más allá de un acercamiento físico y/o sexual.

[...] simplemente fueron las consecuencias de los actos de las dos... Ya estoy entrando en conclusiones de la terapia... esos sentimientos de ese momento fueran un disfraz, simplemente como una alternativa para salir de la relación que ya no me estaba gustando tanto como venía. (Azalea, comunicación personal, 3 de octubre de 2019)

Infidelizados. Antes del acompañamiento terapéutico.

Antes del descubrimiento de la infidelidad, estos participantes ven la infidelidad como un evento que nunca tocará las fibras de su relación. Se consideraban "blindados" dado que estimaban, en su pareja o en su relación, cualidades que los distanciaban de involucrarse con una tercera persona.

Para Girasol, antes de descubrir la infidelidad, esta era un evento lejano. A pesar de tener la experiencia en su familia de origen, consideraba que en su relación era algo difícil de experimentar. Sentía mucha tranquilidad al no ver reflejado en ella y su pareja el estereotipo de sus padres, además, consideraba que una infidelidad era un suceso menor que se podía enfrentar fácilmente. 
Yo decía, mi papá cómo puede ser eso en la calle y luego en la casa tan tranquilo... siempre tuve en la mente que no lo quería repetir; finalmente, llegó a mi vida y me tocó asumirlo y por eso fue como tan destructivo de afrontar. (Girasol, comunicación personal, 3 de diciembre de 2019)

Para Tulipán, antes del descubrimiento, la infidelidad era una experiencia inaceptable dentro de su relación, porque escoger una "buena" pareja le aseguraba blindarse de esa posibilidad. Además, consideraba la fidelidad como una reafirmación de sentimientos del "verdadero" amor. Narró: "Era como inaceptable... uno escoge la novia porque uno la visualiza... como esa pelada buena, como si fuera un moldecito, eso tampoco era bueno... para mí con ella no era posible, cuando hay un verdadero sentimiento, no" (Tulipán, comunicación personal, 4 de septiembre de 2019).

Para Iris, antes del proceso terapéutico, la palabra infidelidad no estaba presente en su diccionario, no consideraba la posibilidad de que su pareja en algún momento pudiese participar en dicho evento, era enaltecido como un ser incapaz de cometer un error como este.

Para mí eso como que no existía, ni había la más mínima probabilidad de que eso sucediera. Endiosado, yo pensaba que cualquier otro, podría cagarla, menos él, cierto... Yo dije, no, este man no puede cometer un error de esos. (Iris, comunicación personal, 20 de septiembre de 2019)

Infidelizados. Después del acompañamiento terapéutico.

El descubrimiento confronta las expectativas previas de los infidelizados, pero la terapia trae para ellos la reflexión de que no es posible blindarse ante la infidelidad, ubica a la pareja en un lugar más humano y la infidelidad como un error que puede acontecer.

Para Girasol, frente al descubrimiento y participar del proceso terapéutico, la infidelidad pasa de ser un suceso menor a uno que produce mucha devastación y dolor. Se resignifica de manera metafórica como "una novela real" con una trama dolorosa, que revela que su pareja no es inmune a la infidelidad ni su relación estaba blindada.

Eso es un circo. Tú vives en una obra de teatro, tú llegas a la casa, tan linda la esposa, pero él está pensando en otra cosa, o sea se viven dos vidas... Es una novela que se lleva a la vida real, se me materializó la novela. (Girasol, comunicación personal, 21 de agosto de 2019)

La transformación del significado para Tulipán llega con la aceptación de que no existen moldes de mujeres buenas o malas, sino de seres humanos vulnerables que 
pueden participar de situaciones para él inaceptables, pero que ahora reconoce que pueden acontecer y construir expectativas de relación de pareja en términos menos idealistas. Afirmó: "Ya me cambio ese 'inaceptable' por 'sí pasa'... le puede pasar a cualquiera... pero pienso que también se puede decidir, evitar. La fidelidad para mí, que antes era... un pilar muy importante, ahora ya no" (Tulipán, comunicación personal, 4 de septiembre de 2019).

En Iris, después del acompañamiento terapéutico, se transforma el significado permeado por asumir la responsabilidad en la idealización de su pareja y en la concepción de esta, como un ser humano que tomó una decisión errada y se equivocó. Se interioriza la idea de que como personas no somos inmunes a cometer faltas. Expresó: "No tenía por qué haber pensado que Lirio no podría nunca cometer un error... él es un humano" (Iris, comunicación personal, 20 de septiembre de 2019), "que definitivamente las personas se pueden equivocar" (Iris, comunicación personal, 8 de noviembre de 2019).

Al triangular los resultados con relación a los significados, en los infidelizados se compadecen con lo expresado en el grupo de discusión: "Yo pensaría que la terapia ayuda como a aclarar esos ideales que tienen, como a aterrizar las expectativas" (Terapeuta 4, comunicación personal, 30 de mayo de 2020).

Mediante la terapia fue posible deconstruir esos significados, replantear ideales y expectativas previas, $y$ ubicarse en otra perspectiva frente a la fidelidad y el amor.

Por otro lado, en estos participantes el espacio terapeutico ayudó, a quien participó en la infidelidad, a dimensionar el daño y las consecuencias que sobrevinieron a su decisión, lo cual concuerda con lo mencionado en el grupo de discusión: "Como que casi nadie sabe cuál es la dimensión de la infidelidad más que el infiel, porque él fue el que tomó una decisión" (Terapeuta 4, comunicación personal, 30 de mayo de 2020).

Para infieles e infidelizados, la terapia fue el espacio para reflexionar sobre los significados de la infidelidad como se describió en el grupo de discusión: "Los significados posibilitan la recuperación es cuando alcanzan a mirar la infidelidad como una crisis que puede volverse una oportunidad" (Terapeuta 3, comunicación personal, 30 de mayo de 2020).

En estos participantes se facilitó llegar a puntos en común sobre el significado, tales como "error", "falta de lealtad", "es de humanos", "es evitable" y, al conjugar la mirada frente al evento, se hizo posible reflexionar sobre la relación, responsabilizarse $\mathrm{y}$ tomar decisiones que replantearon su convivencia.

Finalmente, las narraciones permitieron profundizar y analizar en torno a la transformación de los significados, comprendiéndolos como las creencias y valores que habitan la vida de los seres humanos y que conllevan a las diversas formas de ser y manifestarse (Limón, 2012). En común, se encontró en los infieles heterosexuales una postura de minimización de la infidelidad antes del proceso terapéutico, conformada 
por tres rutas: de la intimidad, la cual tiene relación con mantenerse fiel en el ámbito emocional; de la laxitud, la infidelidad carece de significado y esto conlleva a permear límites; del control, como la convicción de dirigir con certeza la situación sin medir los resultados.

Se perciben estas tres rutas como las creencias que llevaron a la autoaprobación de la vivencia, facilitan no cuestionarse acerca de las consecuencias y dan una especie de tranquilidad, rutas que confluyen en lo que se denominó en el estudio la "ética del infiel", término novedoso, que tiene relación con las creencias y acciones de cómo mantener el evento oculto, concebirlo como algo transitorio y la flexibilidad de irrumpir los límites. A pesar de vivir una especie de conciencia moral frente al evento al mencionarlo como algo que "no estaba del todo bien" o puede suceder mientras no sea descubierto.

La postura de minimización se relaciona con el término de Scuka (2015), de autoengaño, conformado por la minimización, la negación, la supresión o la autojustificación como formas que usa el infiel para convencerse a sí mismo de que su actuar está "bien", lo que puede facilitar desculpabilizarse y alivianar su conciencia.

La participante infiel homosexual no tuvo una postura de minimización, sino que la infidelidad era asociada al involucramiento emocional con la tercera persona, no a la vivencia sexual. La infidelidad emocional ha sido descrita ampliamente en la literatura como aquella donde se dedica atención, tiempo y amor romántico a otra persona que no es la pareja (González et al., 2009; Varela, 2014). Probablemente, esta concepción de la participante estaba dada por los acuerdos que tenían en la relación.

En los infidelizados, a través del análisis de las narrativas, los significados previos se asociaron a una postura de "blindaje o armadura", esto producto de cuatro rutas: de la sacralización, donde la pareja es vista como una divinidad; de la idealización, al concebir al otro como un ser perfecto; del amor, al considerar que cuando se ama se garantiza la fidelidad, y finalmente la no contemplación, como la imposibilidad de vivir esta experiencia. Estas creencias habían forjado la expectativa de que no era posible que la infidelidad llegara a sus vidas, lo cual hizo mucho más difícil la experiencia luego del descubrimiento. Estos hallazgos se compadecen con lo expresado por Rodríguez (2020): a través del amor romántico se idealiza y se dota a la pareja de cualidades superiores que le otorgan un estatus especial.

En los procesos terapéuticos, como expresa Limón (2012), se facilita un espacio para reflexionar la pertinencia de los significados, desmantelar las historias que las personas traen y con esto nace la oportunidad de resignificar o establecer versiones alternas de las creencias e ideas que han venido gobernando su existencia, lo que lleva a una versión distinta o nueva de ver y verse.

Esta reflexión y transformación de los significados en torno a la infidelidad, posterior a la terapia, en los infieles, permite el paso a una postura crítica, basada en el reconocimiento de la falta, así como en la responsabilización de las acciones y 
decisiones. Se concibe que la vivencia también permea a la pareja y la familia; la laxitud se transforma en una concepción de evento evitable, lo cual permite visualizarse como seres humanos que cometieron un error. La postura crítica concuerda con lo expresado en la investigación de Giraldo y Garcés (2013), donde mencionan que, al comprender la magnitud del acto y el dolor desencadenado, se tiene un juicio crítico que permite la incorporación de aprendizajes y el infiel interioriza una nueva ética relacional. En el presente estudio, el analizarse a sí mismos y a la experiencia, los llevó a deconstruir la ética del infiel y dar paso a la verdad, a la sensibilidad necesaria para empatizar con el sufrimiento propio y de la pareja, asumir acciones para subsanar la fractura del "nosotros".

En los infidelizados se transforma el significado, en una postura de responsabilizarse de la idealización, lo que permite la flexibilización de las formas de pensamientos anteriores y el cambio de la visión idealista a reconocer que las personas no son inmunes a la infidelidad, y que este evento no implica necesariamente el desamor, esto permite la concepción de que la pareja se equivocó y que esta decisión lesionó. En semejanza a lo descrito en la investigación por Giraldo et al. (2018), una postura mutua de responsabilización facilita la humanización del vínculo.

Luego de la terapia, las parejas confluyen en la connotación común de la infidelidad como un error, lo que se considera como facilitador en el tránsito hacia la recuperación de la relación, se reconoce la condición de límite propio y de la pareja y se construyen formas que permiten vivir una relación más sólida y humana.

\section{Segunda subcategoría. Vivencias de la infidelidad: transitar del abismo a la grieta.}

Infieles. Antes del acompañamiento terapéutico.

Las emociones y sentimientos que relataron las personas infieles, a través de expresiones metafóricas como choque, el peor mix del universo, desbaratar y la sensación de robo interior, ofrecen una visión que da cuenta del profundo dolor y daño que también a la persona infiel le suscitó el evento: "Digamos que cuando ya hay una situación de choque, que fue lo que vivimos, entonces fue una reacción muy dolorosa... mi imaginario era, esto es algo que no es de siempre"(Clavel, comunicación personal, 21 de agosto de 2019).

El choque, que nombraron los participantes, dimensiona cómo estaban transitando por una ruta y de repente algo de manera abrupta colisionó y detuvo, posiblemente esto relacionado con el descubrimiento de la infidelidad, lo que produjo esa mezcla de emociones intensas, que puso en riesgo la pérdida de aquellos sueños, proyectos y una relación con la persona que se ama. Se dio una colisión contra sí y contra su relación, en la cual se identifican dos vías. La primera, hacía sí mismo por saber que se actuó de manera incorrecta, y esto enfocó la mirada 
hacia adentro y, como relataron, percibirse como una mala persona, con miedo, tristeza y arrepentimiento: "era un arrepentimiento, una decepción de mí... pues me sentía mala, de verdad mala, una persona mala. ¿Por qué?, ni siquiera lo había dimensionado" (Violeta, comunicación personal, 27 de noviembre de 2019).

En la segunda vía, hacia la pareja, emergió dolor al reconocer el daño que vivió esta con la infidelidad, el no ser fiel a afectos, promesas o expectativas de la pareja y la posibilidad de una ruptura definitiva. Como comentó este participante: "Yo pienso que uno no debería hacerle sentir ese dolor a esa persona... como haber desbaratado a la otra persona, haberla destruido... uno no alcanza a dimensionar las cosas hasta que está en ese punto" (Lirio, comunicación personal, 8 de noviembre de 2019).

Esta vivencia podría ser explicada probablemente por varias razones: la no anticipación de las consecuencias, al creer que se tenía bajo control. Otra razón, es la no intencionalidad de herir a la otra persona. Por último, el percibir una mayor conciencia de la posibilidad real de pérdida de la pareja. Por lo tanto, la vivencia frente al descubrimiento y antes de la terapia estuvo rodeada de cuestionarse, autojuzgarse, y la confrontación por el daño y el dolor que siente el otro, y las consecuencias en sí y la relación.

Infieles. Después del acompañamiento terapéutico.

Las emociones y experiencias iniciales dieron cuenta de una suerte de suelo árido inicial que se fue transitando durante el proceso terapéutico y los llevó al camino de recuperación personal y de la relación, motivados por el impulso de reparación. Los participantes infieles expresaron que fue un recorrido difícil en tanto debieron comenzar desde cero: "Entender, ser paciente con muchas cosas, porque es empezar de cero... ir avanzando, de tener todos los días esa paciencia" (Violeta, comunicación personal, 4 de septiembre de 2019).

Después del acompañamiento terapéutico, emergieron términos que se interpretaron como reconstrucción, resistencia, avance y comprensión y dejaron ver que, a pesar de un mix de emociones dolorosas al inicio, el después fue pintado con un panorama más estético, a pesar de las dificultades y el recomenzar. Este desenlace fue fruto de dos caminos: primero, el personal de no vivir dos registros diferentes; segundo, el relacional, que paso a paso migró de ese suelo árido a un suelo abonado para sembrar nuevas posibilidades.

[...] yo siento que ahora somos una mejor relación, porque dimos apertura a muchas cosas, como conocernos un poco mejor, incluso desde los demonios. (Azalea, comunicación personal, 3 de octubre de 2019)

Siento que de verdad con todo el proceso y gracias a lo que hicimos hubo un perdón real. (Azalea, comunicación personal, 17 de octubre de 2019) 
Por lo tanto, se pudo identificar en los infieles una labor de reflexión y reconocimiento de los actos, asumir su responsabilidad y mirarse como un ser frágil y contingente que logró paulatinamente transitar de la devastación a la capacidad de reconstruir y de reparar. Esto acorde con lo expresado en el grupo de discusión: "A través del diálogo que se construye en ese espacio terapéutico se logra tratar de volver a construir como la confianza... el infiel empieza a hacerse cargo de lo ocurrido" (Terapeuta 2, comunicación personal, 30 de mayo de 2020).

La voluntad del infiel para reparar la confianza y la relación lesionada, lo motivó a tomar acciones en pro de cimentar esa reconstrucción, producto de conversar sobre la vivencia, con paciencia y verdad entre otras; por eso, el después estuvo habitado por devenir otro en tanto narrarse como más alegre y abierto, y la relación como más fuerte y cualificada. E1 después implicó, entonces, un nuevo telos, es decir, un nuevo propósito para cada uno y para la relación, que consistía en sobreponerse al tsunami y florecer, reconstruir sobre lo destruido.

Infidelizados. Antes del acompañamiento terapéutico.

En infidelizados, luego del descubrimiento, se evidencia un profundo impacto, con una mezcla de sentimientos tales como odio, rabia, tristeza, ira, la sensación de destrucción propia y del vínculo marital, acompañada de inseguridad y confusión frente a lo que seguiría en la relación y las decisiones personales más apropiadas, también decepción de sí mismo y de la pareja: "Para mí, ha sido la peor experiencia de toda mi vida... era como rabia... como duda, desmotivación mil por ciento, un desamor muy grande... yo tenía como un choque, como tristeza" (Tulipán, comunicación personal, 27 de noviembre de 2019)

Esto conllevó a sentir un profundo golpe a la autoestima y a la relación, la cual se percibía difícil de reconstruir, descrito como un vacío, perderse y perder lo que se creía seguro.

\footnotetext{
Sientes que se destruyó la relación de pareja... como si te tragara un hueco. Entonces a ti te aporrea el ego, los valores, lo que tú eres... Te sientes por el piso, tu autoestima se baja. (Girasol, comunicación personal, 21 de agosto de 2019)

Eso es un momento supremamente doloroso, es que eso acaba con la vida de todo el mundo. (Iris, comunicación personal, 8 de noviembre de 2019)
}

Asimismo, la infidelidad fue asemejada a una experiencia irreal: "Yo sentí que fue como si se me hubiera caído una máscara. Como que algo de mí se fue y se fue al piso... estaba completamente engañado" (Tulipán, comunicación personal, 27 de noviembre de 2019) 
El descubrimiento trae confusión acerca de quién es el otro, parecen desaparecer los sentimientos y lo construido en pareja; a la vez, esa "máscara" posiblemente hace un cuestionamiento de sí mismo, que se reconozca diferente, lo que confronta con la realidad de una vida paralela e inesperada.

Lo anterior, en relación con lo mencionado en el grupo de discusión, hace referencia a que las concepciones previas acerca de la infidelidad pueden afectar la percepción de sí al enfrentar el suceso: "muchas veces esos significados que le dan, tocan con la propia valía, es lo que siento que pasa en un momento de infidelidad cuando ese acto el otro lo siente como un atentado a la valía" (Terapeuta 3, comunicación personal, 30 de mayo de 2020)

Infidelizados. Después del acompañamiento terapéutico.

Para estos participantes, después de la terapia y matizado con el paso del tiempo, hay un importante cambio en lo que fue el peor dolor de sus vidas. Las emociones iniciales se van transformando, logran sentirse más fuertes, más independientes. También, los sentimientos se transforman, pero permiten continuar la vida en pareja, tomando distancia de posturas que blindaban de la infidelidad y ubicándose en un lugar distinto, más agradable para sí. Progresivamente logran apaciguar los recuerdos de la vivencia.

Pero el dolor ha cambiado... cada vez de pronto se diluye más... creo que eso me afectó también en el sentir, en el desapego, en el sentimiento, en la independencia... sé que soy capaz de estar por encima de cualquier cosa, bien conmigo mismo. (Tulipán, comunicación personal, 4 de septiembre de 2019)

Yo pienso que, si a mí me vuelve a pasar eso, yo no sería capaz de, ya de volver, con toda la fortaleza qué me dio ese episodio y con todo lo que enseñó. (Girasol, comunicación personal, 21 de agosto de 2019)

El después viene marcado por percibir que el amor, la relación, los sentimientos y las experiencias se pueden llevar sin que sea un peso, se resignifica la infidelidad como una fuente de aprendizajes y de reconocer otras formas de pensar y decidir con mayor autonomía. El paso por el acompañamiento terapéutico, para los infidelizados, genera una atmósfera de confianza que permite mirarse de forma íntima y ayuda a aceptar la finitud del ser humano, de su pareja que tomó un camino que luego reconoció como equivocado, y también la propia finitud que permitió descubrir que aunque no se participó en la infidelidad también se había fallado en otros aspectos, lo que ayudó a ser más comprensivo con la pareja e impulsó a trabajar para darle una mirada más estética y no arraigarse al pasado: "la terapia individual te permite ver tus 
propios errores y te ayuda a enfrentarlos para poder mejorarlos" (Iris, comunicación personal, 7 de agosto de 2020).

Lo anterior está de acuerdo con lo citado en el grupo de discusión:

\begin{abstract}
[...] en ese caso la infidelidad ya no entraría únicamente en ese campo del daño que me genera el otro, de la mentira, del engaño propiamente sino también como el reconocimiento de la fragilidad y de la necesidad del otro también de contar con apoyo y ayuda. (Terapeuta 4, comunicación personal, 30 de mayo de 2020)
\end{abstract}

La terapia ayudó a infieles e infidelizados a evocar sus capacidades individuales, lo que les permitió verse más fuertes para enfrentar la vivencia, lo cual fue similar a lo enunciado por el grupo de discusión:

\title{
[...] una persona que vivió un episodio de infidelidad y le está doliendo mucho, si bien el otro puede hacer cosas para ayudar, para palear.. un poco compensar, creo que ese elemento que cada quien empiece a gestionar su dolor, es muy importante. (Terapeuta 3, comunicación personal, 30 de mayo de 2020)
}

La metáfora expresada por un participante, "transitar del abismo a la grieta", representa lo que para estas parejas fue la vivencia de la infidelidad y el paso por el proceso terapéutico. En un abismo no puede verse el fondo, lo que dimensiona algo de gran profundidad y sin final, experiencia que se transforma en una grieta, una abertura superficial y estrecha. Este tránsito deja en evidencia que la infidelidad produce una cicatriz, un recuerdo de los movimientos sobre el territorio que ayuda a no perder de vista lo frágil del terreno. Además, da cuenta de la temporalidad, el antes era abismo, el presente y el futuro es horizonte por recorrer, signos de un proceso de sanación de la relación y de sí mismos.

Finalmente, la vivencia antes del proceso terapéutico es descrita como un "tsunami, huracán, agujero negro, una bomba o un choque", lo cual dimensiona los efectos devastadores personales y relacionales, así como el dolor suscitado por el descubrimiento de la infidelidad para ambos, como lo descrito por Schonian (2013) y Scuka (2015).

En los infieles hay un "mix" de emociones, dentro del cual la culpa estuvo presente, al parecer procedente de reconocer que la infidelidad no estaba bien y del daño que se genera en su pareja y en sí mismos, a pesar de que no había tal intencionalidad (Prieto et al., 2012; Molina, 2015). Para los infidelizados, también hay una mezcla de sentimientos, sumada a la lesión de la autoestima y la sensación de destrucción propia y de la idea del "nosotros" construido, igual a lo manifestado por Paz (2013). 
Otra vivencia importante tiene relación con el quiebre de la confianza, que se percibe como la muerte de la relación, hallazgos que concuerdan con las investigaciones de Coop et al. (2005) y Molina (2015).

La transformación de la vivencia luego del proceso terapéutico, se resume en lo que algunos de ellos denominaron de forma novedosa como "trascender", haciendo alusión a moverse de las emociones y experiencias iniciales para dar paso a otras comprensiones en torno a la infidelidad y sus consecuencias; como describe Anderson (1999), la terapia provee nuevas formas de sentir y comprender la historia de las personas, y así elaborar un nuevo futuro. En el caso del infiel, la vivencia durante y después de la terapia viene matizada por reconocer sus elecciones personales y responsabilizarse de las consecuencias, como lo descrito por Johnson (2008), producto de lo cual acepta que la reparación del vínculo y la confianza debe involucrar tenacidad, paciencia, sinceridad y comprensión a su pareja. Por su parte, en infidelizados, trascender a ver la infidelidad como un error da paso a que se resalten atributos de la pareja que lo alejan de la mentira y el engaño, motivando el perdón y la reconstrucción de la relación, sin que esta comprensión y decisión de seguir juntos pretenda omitir el dolor causado o naturalizar el evento, sino aprender de lo vivido y avanzar, acorde con lo expresado por Crawley y Grant (2010) y Abrahamson et al. (2012).

Para estas parejas, el espacio terapéutico permitió una escucha compresiva y un escenario donde emergieron reflexiones, que ayudaron a lograr una responsabilidad en ambos, esto facilitó comprender y reconstruir lo que estaba dañado, dar otro sentido a la experiencia, y trazar un futuro menos álgido tanto en lo personal como en pareja.

\section{Conclusiones}

El proceso terapéutico llevó a las parejas a identificar y deconstruir significados previos, enmarcados en creencias y expectativas individuales, para dar paso a comprensiones comunes en torno a la infidelidad como un error que se inscribe en la falibilidad humana, y este vuelco posibilita emprender un trabajo empático y en equipo que permite embellecer el presente y futuro de ambos.

Las emociones que genera el evento golpean la relación y las parejas, producen una marcada incertidumbre de lo construido y del futuro, sin embargo, el tiempo y el acompañamiento terapéutico posibilitan transitar hacia un lugar de menos dolor, al aceptar responsabilidades y asumir la reconstrucción en pareja.

La terapia ayudó a tramitar las emociones iniciales como son: la tristeza y el dolor en ambos. Además, en el infiel la culpa, el arrepentimiento, la decepción de sí y, en el infidelizado, un daño considerable a la autoestima y la confianza. Se da paso a ver otras cosas más allá de la destrucción y encontrar rutas y planes para reconstruirse 
en lo personal y posibilitar un nuevo horizonte relacional que incluyó: esperanza, paciencia, tenacidad y mayor confianza en sí mismos y en el otro.

En infieles, la terapia permite pasar de una postura laxa frente a la infidelidad y sus consecuencias a una postura crítica que asume la reparación de los daños personales y relacionales. En infidelizados, la terapia ayuda a dar un vuelco a la postura inicial de creerse blindado frente a la infidelidad, a una que reconoce la vulnerabilidad del ser humano y la idealización que se tenía de la pareja.

Por parte de quien participa en la infidelidad, pueden haber ciertos pensamientos y prácticas que llevan a la autoaprobación de la vivencia y que se denominó en esta investigación "la ética del infiel" que luego del proceso terapéutico, aquello considerado banal e inocuo, toma una forma de seriedad, gravedad y situación evitable.

Entre las implicaciones, este estudio describe nuevas formas de enunciar creencias previas frente al evento, tales como la postura de "minimización" y la de "blindaje". El uso de estos conceptos pueden ser herramientas para el terapeuta que, al traerlos a la conversación con las parejas, permitan encontrar posibles semejanzas o diferencias con respecto a sus propios significados y vivencias, lo cual podría ampliar las comprensiones en torno a las expectativas previas que se traen en los momentos iniciales y hacen más difícil aceptar el acontecimiento y sus consecuencias, pero así mismo posibilitan reconocer y cimentar otras rutas, que faciliten asumir otras posturas que lleven a la reconstrucción del vínculo.

Así mismo, el concepto de la "ética del infiel" puede ser útil para el terapeuta al nombrar prácticas que pueden lesionar a la propia persona y a la pareja, pero también para el infiel puede constituirse en un llamado a la autoevaluación, a la autocrítica, al reconocimiento de que los seres humanos frente a situaciones que cuestionan pueden forjar su propio marco de referencia y mantenerse allí como una manera de autoaprobarse, y en algunos casos de justificar acciones que pueden trasgredir. En terapia, a través de las conservaciones, pueden darse reflexiones que faciliten visibilizar estas prácticas y a partir de ahí las personas puedan tomar decisiones sobre estas.

Para futuras investigaciones se sugiere un mayor volumen de parejas participantes, incluyendo parejas diversas y multiculturales.

\section{Agradecimientos}

Gracias a los participantes del estudio, por brindarnos el espacio para compartir generosamente sus vivencias. De igual forma, gracias a los terapeutas participantes por contribuir mediante su experiencia a nuestra investigación. 


\section{Referencias}

Abrahamson, I., Hussain, R., Khan, A. y Schofield. (2012). What Helps Couples Rebuild Their Relationship After Infidelity? Journal of Family, 33(11), 1494-1519.

Alfonso, L.y Hernández, J. (2020). Significados del amor e historias de infidelidad en parejas que inician un proceso de psicoterapia. Divers.: Perspect. Psicol., 16(1), 80.

Anderson, H. (1999). Conversación, lenguaje y posibilidades. Un enfoque posmoderno de la terapia. Amorrortu.

Camacho, J. (2004). Fidelidad e infidelidad en las relaciones de pareja. Dunken. http://www.fundacionforo. com/pdfs/archivo42.pdf

Charny, I. y Parnass, S. (2008). The Impact of Extramarital Relationships on the Continuation of Marriages. Journal of Sex E Marital Therapy, 21(2), 37-41.

Coop, K., Baucom, D. y Snyder, D. (2005). Treating Couples Recovering From Infidelity: An Integrative Approach. Journal of Clinical Psychology, 61(11), 1393-1405.

Crawley, J. y Grant, J. (2010). Terapia de pareja. El yo en la relación. Morata.

Creswell, J. y Poth, C. (2016). Qualitative inquiry and research design: Choosing among five approaches. Sage publications.

Datexco. (2012). Colombia, un país de infieles y engañados. El Tiempo. https://www.eltiempo.com/ archivo/documento/CMS-12142365

Dugal, C., Bakhos, G., Bélanger, C. y Godbout, N. (2018). Cognitive-Behavioral Psychotherapy for couples: An Insight into the treatment of Couple Hardships and Struggles. Intechopen.

Fincham, F. y May, R. (2016). Infidelity in romantic relationships. Current Opinion in Psychology, 13, 70-74.

Garciandía, J. y Samper, J. (2012). Las infidelidades: aprendiendo desde dentro de las conversaciones terapéuticas. Rev. Colomb. Psiquiat., 41(3), 496-520.

Giraldo, C.y Garcés, M. (2013). Emociones asociadas al descubrimiento de la infedilidad: de la felicidad a la infelicidad. Revista Facultad de Trabajo Social, 29(29), 143-157.

Giraldo, C., Garcés, M. y Posada, I. (2018). La infidelidad: un laberinto con salida. Reflexiones construidas en el proceso terapéutico. Revista de Trabajo Social, (28), 53-69.

González, J., Martínez, A., y Martínez, D. (2009). Factores psicológicos asociados a la infidelidad sexual y/o emocional y su relación a la buisqueda de sensaciones en parejas puertorriqueñas. Revista Puertorriqueña de Psicología, 20, 168-189.

Hernández, R., Fernández, C. y Batista, P. (2010). Metodología de la investigación. McGraw-Hill Education.

Jiménez, M. (2016). Transformación de significados con respecto a sí mismo y a la experiencia de pareja de mujeres y hombres que han vivido historias de infidelidad (tesis de maestría). Pontificia Universidad Javeriana, Bogotá, Colombia.

Johnson, S. (2008). Práctica de la terapia matrimonial concentrada emocionalmente. creando conexiones. Routledge Taylor \& Francis Group. 
Infidelidad: pasar del abismo a la grieta luego del acompañamiento terapéutico

Limón, G. (2012). La terapia como diálogo hermenéutico y construccionista. Prácticas de libertad y decocostrucción en los juegos relacionales, de lenguaje y de significado. Taos Institute Board of Directors.

Luyens, M. y Vansteenwegen, A. (2001). Intervenciones terapéuticas en parejas con problemas por affairs extramatrimoniales: un modelo de fases. Revista Argentina de Sexualidad Humana, 1(7-16).

Molina, D. (2015). "Factores que contribuyen a que una experiencia de infidelidad tenga resultados positivos en una pareja": perspectivas de profesionales en el área de la salud mental que trabajan con parejas (tesis de pregrado). Universidad San Francisco de Quito, Ecuador.

Morrissey, L., Wettersten, K. y Brionez, J. (2018). Qualitatively Derived Definitions of Emotional Infidelity Among Professional Women in Cross-Gender Relationships. Psychology of Women Quarterly, 43(1), 73-87.

Paz, N. (2013). Atención terapéutica a la pareja: la infidelidad, una herida ética. Familia, 47, 65-81.

Pérez, C., Ruiz, R. y Parra, C. (2014). Efecto de una intervención cognitivo conductual en el conflicto marital por infidelidad. Psychologia. Avances de la disciplina, 8(2), 23-37.

Posada, I. y Noreña, D. (2015). La infidelidad virtual como una oportunidad de resignificación positiva. Rev. Fac. Nac. Salud Pública, 116-122.

Prieto, M., Carrasco, M., Cagigal, V., Gismero, E., Martínez, P. y Muñoz, I. (2012). E1 perdón como herramienta clínica en terapia individual y de pareja. Clínica Contemporanea, 3(2), 121-134.

Ramos, G. (2013). Abordaje terapéutico en un caso de infidelidad de una pareja de adultos a partir del modelo Resolución de Problemas de Palo Alto (tesis de especialización). Universidad de Palermo, Buenos Aires, Argentina.

Rodríguez, T. (2020). La infidelidad en internet: un panorama sobre el fenómeno y su investigación. Digithum, (25), 1-15.

Roos, L., O'Connor, V., Canevello, A. y Bennett, J. (2019). Post-traumatic stress and psychological health following infidelity in unmarried young adults. Stress and Health, 1-12.

Schonian, S. (2013). Perceptions and definition of infidelity: a multimethod study (tesis de maestría). University of Nevada, Las Vegas.

Scuka, R. (2015). A Clinician's Guide to Helping Couples Heal from the Trauma of Infidelity. Journal of Couple E Relationship Therapy, 16(2), 37-41.

Urganc1, Betül y Sakman, Ezgi. (2019). Perceptions of Infidelity. Springer, 1-3.

Varela, M. (2014). Estudio sobre infidelidad en la pareja: Análisis de contenido de la literatura. Alternativas en psicología, (30), 36-49.

Warach, B. y Josephs, L. (2019). The aftershocks of infidelity: a review of infidelity-based attachment trauma. Sexual and Relationship Therapy, 1-23. 